Supplement of Atmos. Chem. Phys., 16, 12411-12424, 2016

http://www.atmos-chem-phys.net/16/12411/2016/

doi:10.5194/acp-16-12411-2016-supplement

(C) Author(s) 2016. CC Attribution 3.0 License.

(c) (i)

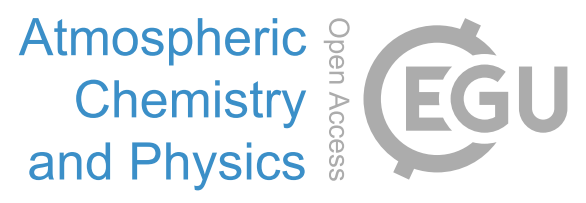

Supplement of

\title{
What controls the low ice number concentration in the upper troposphere?
}

\section{Cheng Zhou et al.}

Correspondence to: Cheng Zhou (zhouc@umich.edu)

The copyright of individual parts of the supplement might differ from the CC-BY 3.0 licence. 


\section{Supplementary figure}
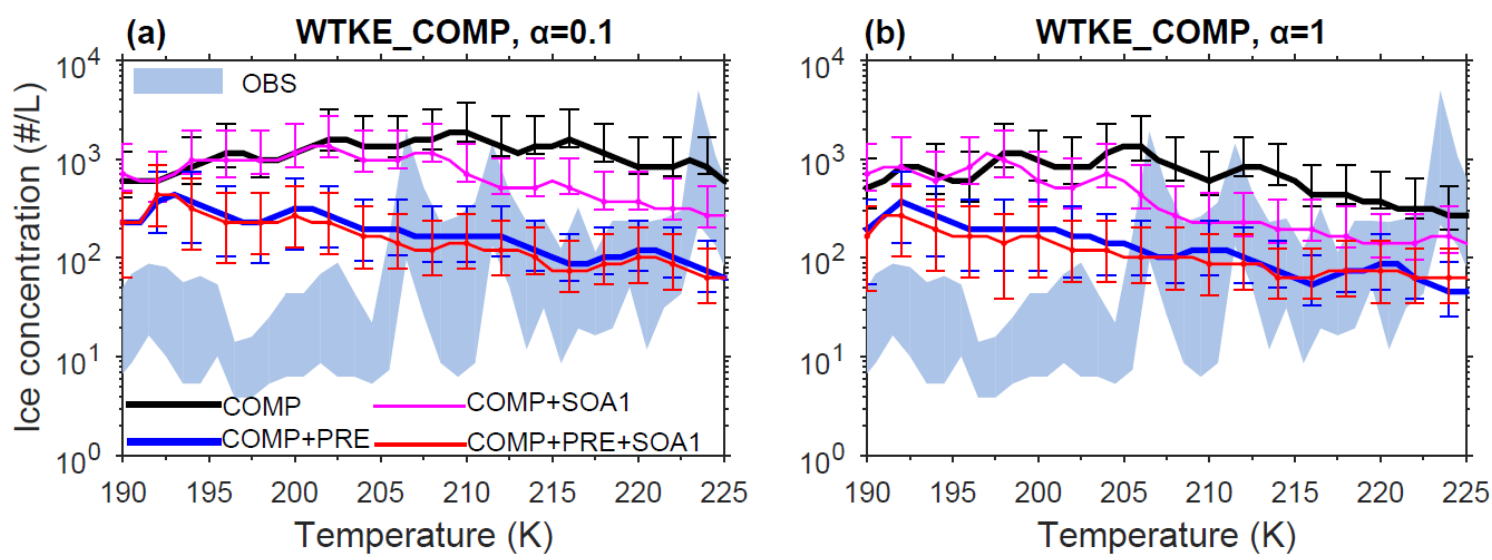

Figure S1 Same as Figure 5 except 1\% of total SOA acting as IN. 